\title{
Arazi Toplulaştırma Projelerinde Parsel Şekillerinin Analizi: Niğde Misli Ovası 2. Kısım Yıldıztepe Örneği
}

\section{Rengin BAYRAM1 1 (D), Hasan DEĞİRMENCİ 2 \\ ${ }^{1}$ Yılmaz Cora Harita İnşaat San. ve Tic. Ltd. Şti, Ankara, ${ }^{2}$ Kahramanmaraş Sütçü İmam Üniversitesi Ziraat Fakültesi Biyosistem Mühendisliği Bölümü \\ $\triangle$ : degirmenci@ksu.edu.tr}

\section{ÖZET}

$\mathrm{Bu}$ çalışmanın amacı arazi toplulaştırma (AT) öncesi ve sonrası hazine, mera ve şahıs parsellerindeki şekilsel değişimi belirlemektir. Niğde Misli Ovası 2. Kısım Yıldıztepe arazi toplulaştırma projesi materyal olarak alınmıştır. Çalışmada AT öncesi ve sonrası parsel şekillerindeki geometrik değişiklik şekil indeksi (SI), fraktal büyüklük indeksi (FD), şekil faktörü (FORM) ve kare piksel ölçeği $(\mathrm{SqP})$ göstergeleri ile incelenmiştir. Proje alanı içerisindeki parseller hazine, mera ve şahıs olarak ayrılarak bu gruplar içerisinde AT öncesi ve sonrası oluşan indeksler karşılaştırılmıştır. AT öncesi ve sonrasında SI, FD ve FORM göstergeleri optimum değere yaklaşmıştır. Ancak SqP tarım arazilerini değerlendirmede başarılı bulunmamıştır. Ayrıca incelenen bazı parsellerde şekil indeksi göstergelerinin optimum değere yaklaşsa bile geometriksel şekilleri ifade etmekte başarısız bulunmuştur. Sonuçta SI, FD ve FORM göstergelerinin AT çalışmalarında parsel şekillerini incelemek amaçlı kullanılabileceği belirlenmiştir.
DOI:10.18016/ksudobil.369729

\section{Makale Tarihçesi}

Geliş Tarihi : 21.12.2017

Kabul tarihi : 09.02.2018

\section{Anahtar Kelimeler \\ Arazi parçalılığı, \\ Arazi toplulaştırma, \\ Parsel endeksi, \\ Şekil analizi}

\section{Araştırma Makalesi}

\section{Analysis of Parsel Shapes in Land Consolidation Projects: A Case Study Of Niğde Misli Plain 2. Kısım} Yildıztepe

\begin{abstract}
Aim of this study was to determine any chances in parcel shape prior and after land consolidation (LC). In this study, Niğde Misli Plain 2. Kısım Yildiztepe Project was taken as material. In the scope of the study, the geometrical change in the parcel shapes prior and after LC was examined with shape index (SI), fractal dimension (FD), form factor (FORM) and square pixel metric ( $\mathrm{SqP})$ indicators. The parcels in the project area were separated into public land, pasture and field, and the indices formed prior and after LC were compared among these groups. SI, FD and FORM indicators before and after land consolidation have reached about optimum value. But $\mathrm{SqP}$ was not found as an indicator to recognize agricultural parcel shape. It has been found that some of the parcels examined have failed to express geometrical shapes even if their shape index approaches the optimum value. As a result, SI, FD and FORM indices can be used to assess agricultural parcel shapes in land consolidation.
\end{abstract}

\author{
Article History \\ Received : 21.12.2017 \\ Accepted : 09.02.2018
}

\section{Keywords \\ Land fragmentation, Land consolidation, Parcel index, Shape analysis}

\section{Research Article}

To Cite : Bayram R, Değirmenci H 2018. Arazi Toplulaştırma Projelerinde Parsel Şekillerinin Analizi: Niğde Misli Ovası 2. Kısım Yıldıztepe Örneği. KSÜ Tarim ve Doğa Derg 21(3):500-510, 2018. DOI:10.18016/ ksudobil.369729

\section{GíRIS}

Çeşitli nedenlerle ekonomik olarak tarımsal faaliyetleri yapmaya imkân vermeyecek biçimde parçalanmış, dağılmış, bozuk şekilli parsellerin modern tarım işletmeciliği esaslarına göre ve sulama hizmetlerinin geliştirilmesi için en uygun biçimde birleştirilmesi, şekillendirilmesi ve yeniden düzenlenmesi işlemine "arazi toplulaştırması" denilmektedir (Anonim, 2017).

Arazi toplulaştırmasının amacı, daha az zaman, işgücü ve sermaye kullanımı ile üretim faktörlerinden en iyi biçimde yararlanarak tarımsal üretimi ve tarım işletmelerinin verimliliğini artırmak ve kırsal kesimdeki nüfusun hayat standartlarını 
yükseltmektir. Arazi parçalılığının ve dağınıklığının giderilmesi, şekillerinin düzeltilmesi, çiftçinin çalışma koşullarının iyileştirilmesi ve diğer hizmetlerin araziye ulaştırılması gibi yapısal önlemlerin alınması arazileri yeniden düzenleme firsatı yaratan arazi toplulaştırması çalışması çerçevesinde yürütülebilmektedir.

Yapılan araştırmalar ve durum analizleri tarım arazilerinin rasyonel kullanımında karşılaşılan temel sorunları; uygun olmayan parsel büyüklükleri, tarımsal mekanizasyon için uygun olmayan parsel şekilleri, ulaşım sorunu olan parseller ve aynı arazi sahibine ait parsellerin dağınıklığı olarak belirlemişlerdir. $\mathrm{Bu}$ sorunların çözümünde arazi toplulaştırma en önemli araç orak görülmektedir. Yapılan arazi toplulaştırma projelerinin öncesi ve sonrası parsel şeklilerinin araştırılması ve bu parsellerin tarımsal işletmecilik yönünden karşılaştırılması her geçen gün önem kazanmaktadır. Yapılan literatür çalışmalarında Dünya'da ve ülkemizde arazi toplulaştırma öncesi ve sonrası parsel şekilleri üzerine yapılmış çok az araştırma yapıldığı tespit edilmiştir.

Parsellerin şekilleri tarımsal mekanizasyonu ve parsel içi sulamayı doğrudan etkilemektedir. Uygun şekilde olmayan bir parselin hangi yöntemle olursa olsun sulanabilmesi için daha fazla işçilik ve malzeme gerektirecektir. $\mathrm{Bu}$ durum üretim maliyetlerini arttıracaktır. Parsellerin şekilleri tarımsal mekanizasyon açısından önem taşımaktadır. Arazilerin şekilleri ile işlenme zamanlarında oluşabilecek kayıpların belirlenmesi amacıyla birçok çalışma yapılmıştır (Arslan ve Tunca, 2013).

Parsel şeklinin iş verimi üzerindeki etkisi konusunda yapılmış bir çalışmaya göre dikdörtgen şeklindeki bir parselde iş verimi 100 kabul edildiğinde bu verimin yamuk için 96.7'ye, düzensiz parsel şekli için 90.9'a düştüğü saptanmıştır. Aynı çalışmada dikdörtgen şeklindeki parselde birim alanın işlenmesi için gerekli çalışma süresi 100 alındığında bu sürenin yamuk şekli için 103.4'e, düzensiz parsel şekli için ise 109.4'e yükseldiği belirlenmiştir (Boyacıoğlu, 1975). Bu yüzden tarımda ideal parsel şeklinin dikdörtgen olduğu belirtilmiştir (Kara 1984). Yapılan çalışmalarda, dikdörtgen şeklindeki parsellerde üçgen şeklindeki parsellere kıyasla \%50'ye yakın işgücü ve \%20'ye yakın verim artışı sağlandığı tespit edilmiştir. Kayseri-Pınarbaşı arazi toplulaştırma projesinde AT öncesi \%44 olan dikdörtgen parseller, toplulaştırma sonrası \%73'e yükselmiştir (Boztoprak ve ark., 2015). Eskişehir Beyazaltın köyü arazi toplulaştırmasında toplulaştırmadan önce dikdörtgen şekilli parsel oranı \%6.82 iken, toplulaştırmadan sonra \%89.50'ye yükselmiştir. Proje sahasında arazi toplulaştırması sonrasında dikdörtgen şekilli parsel sayısı oldukça artmıştır (Sönmezyıldız, 2012). Örencik köyünde toplulaştırmadan önce 318 parselin şekilsiz, 236 parselin yamuk, 69 parselin dikdörtgen, 19 parselin kare ve 8 parselin üçgen olduğu görülmektedir. Dikdörtgen parsel oranı toplulaştırmadan önce \%11 iken, toplulaştırmadan sonra \%55 e yükselmiştir. Dedeli köyünde toplulaştırmadan önce 313 parselin şekilsiz, 157 parselin yamuk, 41 parselin dikdörtgen, 7 parselin kare ve 20 parselin üçgen olduğu görülmektedir. Dikdörtgen parsel oranı toplulaştırmadan önce $\% 8$ iken toplulaştırmadan sonra \% 44 e yükselmiştir. (Arslan ve Tunca, 2013). Yoğunlu'nun (2013) bildirdiğine göre; bazı Avrupa Ülkelerinde yapılan araştırmalara göre; arazi toplulaştırmasının sağladığı net gelir artışı Almanya'da \%20-25, İsviçre'de \%10-25, İspanya'da \%31-36, Hollanda'da ise \%10 olarak saptanmıştır.

$\mathrm{Bu}$ araştırmada; arazi toplulaştırma projelerinde parsel şekillerinin sayısal göstergelerle değerlendirilmesi amaçlanmıştır. Araştırmada Niğde Misli Ovası 2. Kısım Yıldıztepe arazi toplulaştırma projesi materyal olarak alınmıştır. Çalışmada AT öncesi ve sonrası parsel şekillerinin sayısal ve geometrik değişimini incelemek amacıyla şekil indeksi, fraktal büyüklük indeksi, şekil faktörü ve kare piksel ölçeği göstergeleri kullanılmıştır. Kısacası AT sonrasında şekil göstergelerinin değişimi gözlenerek parsel şekillerin değerlendirilmesi amaçlanmıştır.

\section{MATERYAL ve METOT}

\section{Materyal}

Araştırma Niğde ili merkeze bağlı Yıldıztepe Köyünde yürütülmüştür. Yıldıztepe Köyü 2012 yılında Tarım Reformu Genel Müdürlüğünce arazi toplulaştırma kapsamına alınmıştır. Araştırma alanı yaklaşık Niğde merkeze $35 \mathrm{~km}$ uzaklıktadır. Köy nüfusu 2452 olup 1069 hane bulunmaktadır. Bölgede karasal iklim özellikleri görülmektedir. Kış ayları genellikle çok soğuk ve kar yağışl yazları ise sıcak ve kuraktır. Araştırma alanında yıllık ortalama sıcaklık $9.4^{\circ} \mathrm{C}$, en yüksek sıcaklık $38.5^{\circ} \mathrm{C}$, en düşük sicaklık $-19^{\circ} \mathrm{C}$ ve yıllık yağış miktarı yaklaşık 362 mm'dir. Araştırma alanının konumu Şekil 1'de ve AT öncesi ve sonrası mülkiyet durumu Çizelge 1'de verilmiştir.

Araştırma alanı tarım arazilerinde ekili ürünlerin çoğunluğunu buğday, yulaf, arpa, fasulye, nohut (baklagiller), patates (sanayi bitkisi), yonca (yem bitkisi), kuru soğan ve sarımsak oluşturmaktadır. Araştırma alanı toplulaştırma proje öncesi ve sonrası parselasyon bilgileri Çizelge 2'de verilmiştir.

\section{Metot}

Araştırmada parsel şekillerini belirlemek amaciyla kullanılan göstergeler Çizelge 3'te verilmiştir. SI'nın birimi yoktur, SI 1'e eşit olduğunda veya yaklaştığında dairesel, kare alanı ifade ederken 1'den uzaklaşan değerler düzensiz ve şekilsiz alanları tanımlamaktadır 
(McGarigal ve ark., 1995; Gonzalez ve ark., 2004, 2007; Aslan ve ark., 2007; Libecap ve Lueck 2009). Parsel şekillerini değerlendirmek amacıyla FD birçok araştırmacının kullandığı bir yöntemdir (Aslan ve ark., 2007;). FD 1-2 arasında değerler almaktadır ve bu değerler 1'e yaklaştıkça kare gibi düzgün alanları ifade ederken 2'ye yaklaşan değerler ise düzgün olmayan şekilleri göstermektedir (Gonzalez ve ark., 2004; Aslan ve ark., 2007; Libecap ve Lueck 2009; Arslan ve ark., 2017). FORM değerleri 1 ve 1'den daha küçük değerler almaktadır. Bir şeklin FORM değeri 1'e yaklaştığında kare dikdörtgen gibi düzgün geometrik şekilleri ifade ederken 1'den uzaklaşan değerler düzensiz şekilleri ifade etmektedir (Russ, 2002; Lewis ve ark., 1997). Frohn (2006) şekil karmaşılklığını belirlemek için $\mathrm{SqP}$ göstergesini önermiş ve çalışmasında kullanmıştır. SqP değerleri 0.125 ile 1 arasında değişmektedir. Sıfira yaklaşan değerler kare gibi düzgün şekilleri ifade ederken sıfırdan uzaklaşan değerler daha düzensiz şekilleri ifade etmektedir. Arazi toplulaştırması öncesi ve sonrasında oluşan parsel şekillerinin belirlenmesinde NetCAD 5.1, LiTOP ve Esri ArcMAP 10.5 programlarından yararlanılmıştır.

Çizelge 1. Yıldıztepe mülkiyet durumu

\begin{tabular}{|c|c|c|c|c|c|c|}
\hline \multirow{2}{*}{$\begin{array}{l}\text { Mülkiyet } \\
\text { Şekilleri }\end{array}$} & \multicolumn{2}{|c|}{ Parsel Sayısı } & \multicolumn{2}{|c|}{ Arazi (ha) } & \multirow{2}{*}{$\begin{array}{c}\begin{array}{c}\text { Miktarl } \\
(\%)\end{array} \\
\text { AT } \\
\text { Öncesi }\end{array}$} & \multirow{2}{*}{$\begin{array}{c}\begin{array}{c}\text { Miktar } \\
(\%)\end{array} \\
\text { AT } \\
\text { Sonras }\end{array}$} \\
\hline & $\begin{array}{c}\mathrm{AT} \\
\text { Oncesi }\end{array}$ & $\begin{array}{c}\text { AT } \\
\text { Sonras! } \\
\end{array}$ & $\begin{array}{c}\mathrm{AT} \\
\text { Oncesi }\end{array}$ & $\begin{array}{c}\mathrm{AT} \\
\text { Sonrası } \\
\end{array}$ & & \\
\hline Şahıs Arazileri & 5958 & 3094 & 4282.7 & 3850.0 & 88.15 & 87.76 \\
\hline $\begin{array}{l}\text { Hazine } \\
\text { Arazileri }\end{array}$ & 233 & 242 & 376.5 & 339.8 & 7.75 & 7.75 \\
\hline Mera Arazileri & 23 & 4 & 167.8 & 166.9 & 3.46 & 3.81 \\
\hline $\begin{array}{l}\text { Köy Tüzel } \\
\text { Kişiliği } \\
\text { Arazileri }\end{array}$ & 8 & 7 & 30.8 & 29.8 & 0.64 & 0.68 \\
\hline Toplam & 6222 & 3347 & 4858.0 & 4386.7 & 100 & 100 \\
\hline
\end{tabular}

Çizelge 2. Parselasyon bilgileri

\begin{tabular}{l|cc}
\hline & AT Öncesi & AT Sonrası \\
\hline Parsel sayısı & 6222 & 3350 \\
Ortalama parsel büyüklüğü (da) & 7.81 & 13.10 \\
Ortalama işletme büyüklüğü (da) & 24.23 & 21.88 \\
Toplam malik sayısı & 15053 & \\
Toplam işletme sayısı & 2006 & \\
Toplulaştırma oranı (\%) & 46.14 & \\
\hline
\end{tabular}

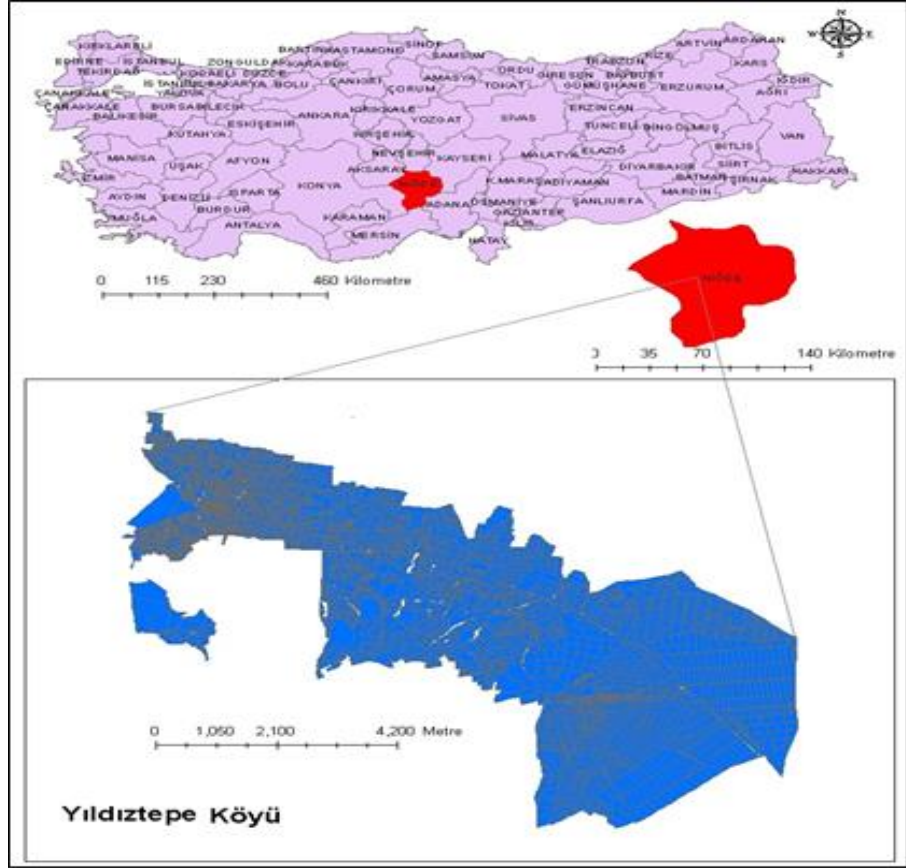

Şekil 1. Araştırma alanı lokasyon haritası 
Cizelge 3. Parsel şekil göstergeleri

\begin{tabular}{|c|c|c|c|c|}
\hline Göstergeler & Formül & $\begin{array}{c}\text { Optimum } \\
\text { değer }\end{array}$ & $\begin{array}{c}\text { Değer } \\
\text { aralıkları } \\
\end{array}$ & Tanımlar \\
\hline Şekil indeksi (SI) & $S I=\frac{\mathrm{p}_{\mathrm{i}}}{2 \sqrt{\pi \mathrm{a}}}$ & 1 & $1 \leq \mathrm{SI} \leq \infty$ & \multirow{4}{*}{$\begin{array}{l}\mathrm{p}=\text { Parsel çevre } \\
\text { uzunluğu } \\
\mathrm{a}=\text { Parsel alanını ifade } \\
\text { etmektedir. }\end{array}$} \\
\hline Fraktal büyüklük indeksi (FD) & $\mathrm{FD}=\frac{2 \ln p_{\mathrm{i}}}{\ln \mathrm{a}_{\mathrm{i}}}$ & 1 & $1 \leq \mathrm{FD} \leq 2$ & \\
\hline Şekil faktörü (FORM) & $\mathrm{FORM}=\frac{4 \pi \mathrm{a}}{\mathrm{p}^{2}}$ & 1 & $0<$ FORM $<1$ & \\
\hline Kare piksel ölçeği (SqP) & $\mathrm{SqP}=\frac{1-(4 \sqrt{\mathrm{a})}}{\mathrm{p}}$ & 0 & $0 \leq \mathrm{SqP} \leq 1$ & \\
\hline
\end{tabular}

\section{BULGULAR ve TARTIŞMA}

AT Öncesi ve Sonrası Parsellerin Geometrik Şekilleri AT öncesi ve sonrası oluşan haritalar LiTOP paket programinda analiz edilmiş ve Şekil 2'de görüldüğü gibi parsellerin geometrik şekilleri belirlenmiştir. Analiz sonucunda AT öncesi şekilsiz parsel sayısı 1391 iken AT sonrası 340'a, üçgen parsel sayısı AT öncesi 208 iken AT sonrası 45 adet gerçekleşmiştir. Çelebi
(2010) Karaman ilinde yapmış olduğu çalışmada, düzgün dörtgen ve yamuk şeklindeki parsel oranı toplulaştırmadan önce Yuvatepe'de 82.9\%, Bölükyazı'da \%62.2, Hamidiye'de \%79.3, Kılbasanda \%79.5 olarak bulmuştur. Toplulaştırmadan sonra bu oranlar sirasiyla $\% 78.5, \% 81.4, \% 91.9$ ve $\% 87.7$ olarak gerçekleşmiştir.

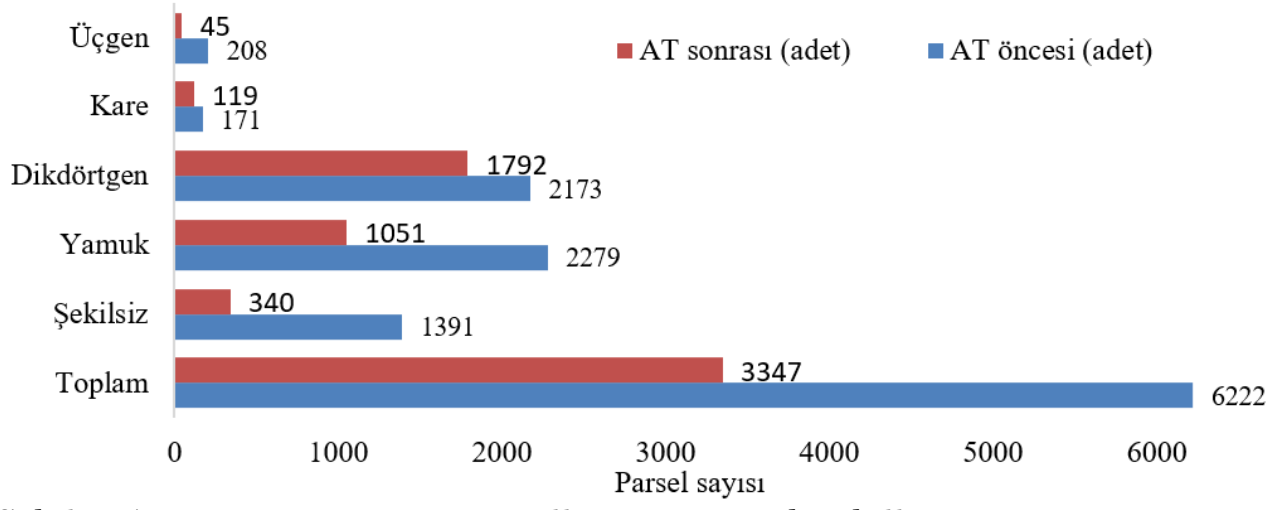

Şekil 2. AT öncesi ve sonrası parsellerin geometrik şekilleri

AT öncesi ve sonrası parsel şekilleri ArcMAP 10.5 programinda analiz edilmiştir. Analiz sonucunda AT öncesi ve sonrası parseller hazine, mera ve şahıs parselleri olarak sınıflandırılmıştır. Analizde ayrıca her bir arazi kullanım sinıfına göre AT öncesi ve sonrası parsellerin genel durumu ayrı ayrı Şekil 3’te verilmiştir.

AT öncesi ve sonrasında hesaplanan SI, FD, FORM ve $\mathrm{SqP}$ göstergelerini karşılaştırmalı olarak göstermek amacıyla kutu grafiği (Box Plot) kullanılmıştır. Şekil 4 'te gösterilen kutu grafiği incelendiğinde AT öncesi hazine parsellerinin SI değerlerinin \%95'inin 1.42361.5335 , AT sonrast ise \%95'inin 1.4354-1.5616 arasında toplandığ 1 görülmektedir. AT öncesi hazine parsellerinin ortalama, maksimum ve minimum SI değerleri sırasıyla 1.4786, 3.6431 ve 1.1092; AT sonrası ise $1.4985,4.3217$ ve 1.1288 olarak hesaplanmıştır. AT öncesi mera parsellerinin SI değerlerinin \%95'inin 1.4698-1.9157, AT sonrası ise \%95'inin 1.1166-2.1685 arasında toplandığı görülmektedir. 


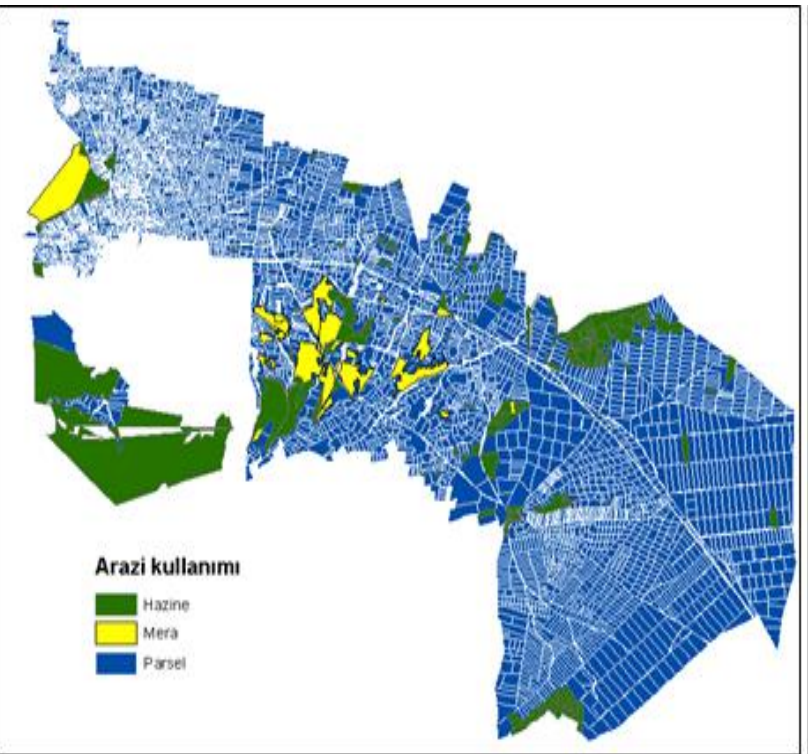

AT öncesi arazi kullanum

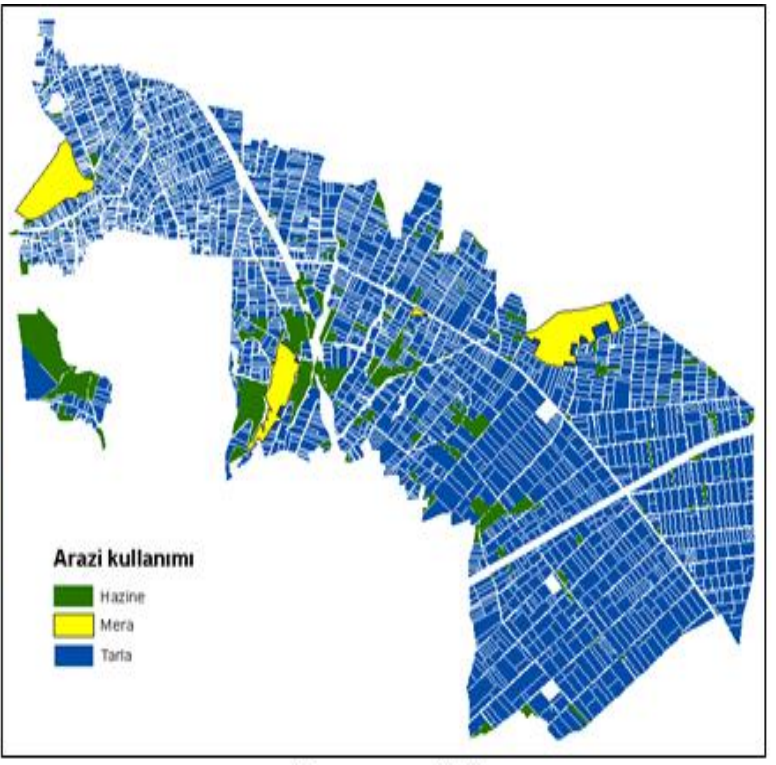

AT sonras1 arazi kullanimu

Şekil 3. AT öncesi ve sonrası arazi kullanımı
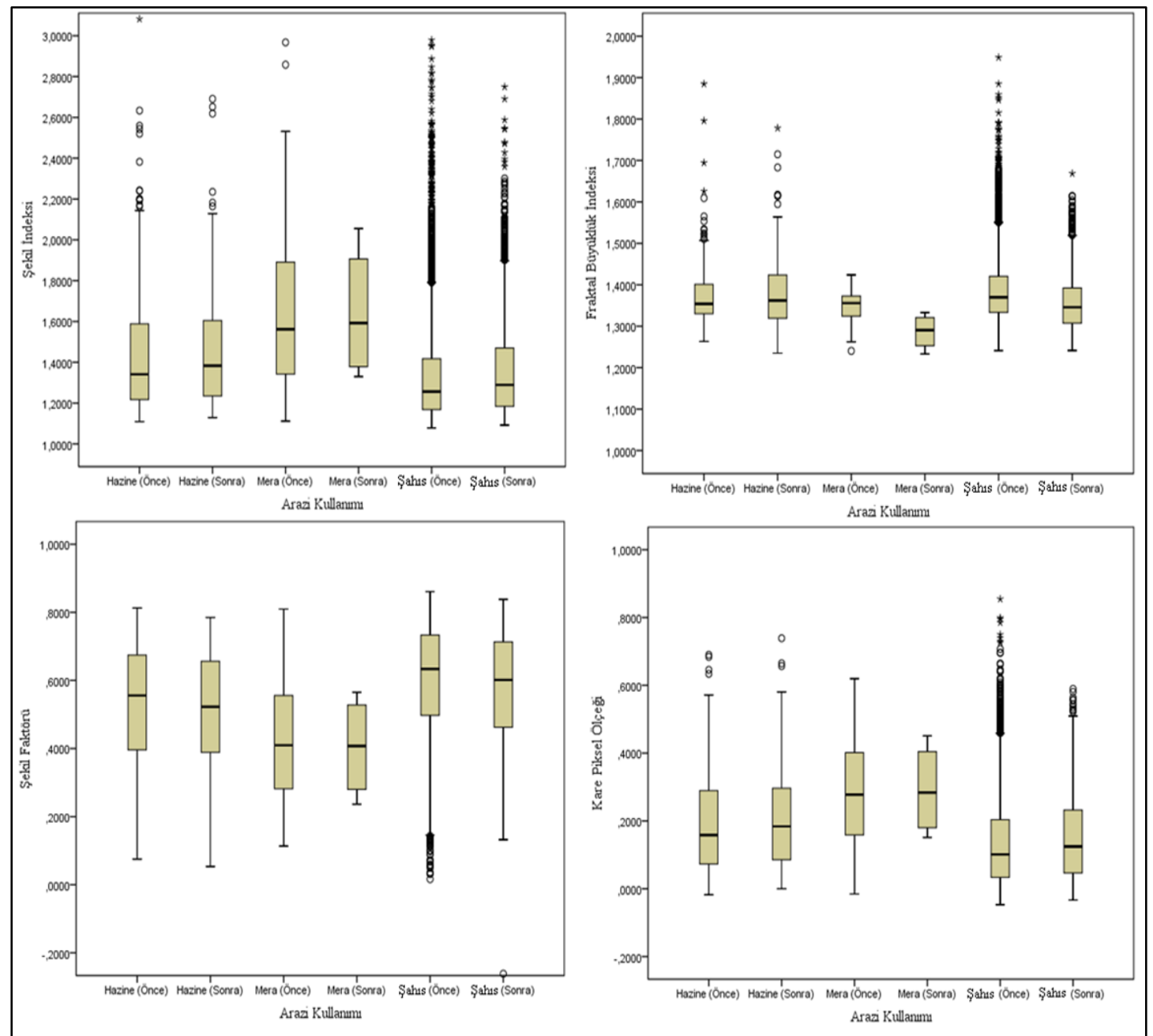

Şekil 4. AT öncesi ve sonrası SI, FD, FORM ve SqP kutu grafiği 
AT öncesi mera parsellerinin ortalama, maksimum ve minimum SI değerleri sirasiyla 1.6927, 2.9675 ve 1.1115; AT sonrası ise $1.6425,2.0556$ ve 1.3301 olarak hesaplanmıştır. AT öncesi şahıs parsellerinin SI değerlerinin \%95'inin 1.3372-1.3524, AT sonrası ise \%95'inin 1.3538-1.3701 arasında toplandiğ görülmektedir. AT öncesi şahıs parsellerinin ortalama, maksimum ve minimum SI değerleri sirasiyla 1.3448, 7.7580 ve 1.0779 ; AT sonrası ise $1.3619,2.7497$ ve
1.0924 olarak hesaplanmıştır. Şekil 5’te AT öncesi ve sonrası durumda parsellerin alanlarının büyüdüğü ve SI değerlerinin 1'e yaklaştığı görülmektedir. Şahıs parselleri arasında AT öncesi ve sonrası durumda SI indeksi değerleri istatiksel olarak farklıdır $(\mathrm{P}<0.05)$. SI indeksi değerleri AT öncesi ve sonrası hazine ve mera parsellerinde istatiksel olarak farklılık göstermemektedir $(\mathrm{P}>0.05)$.

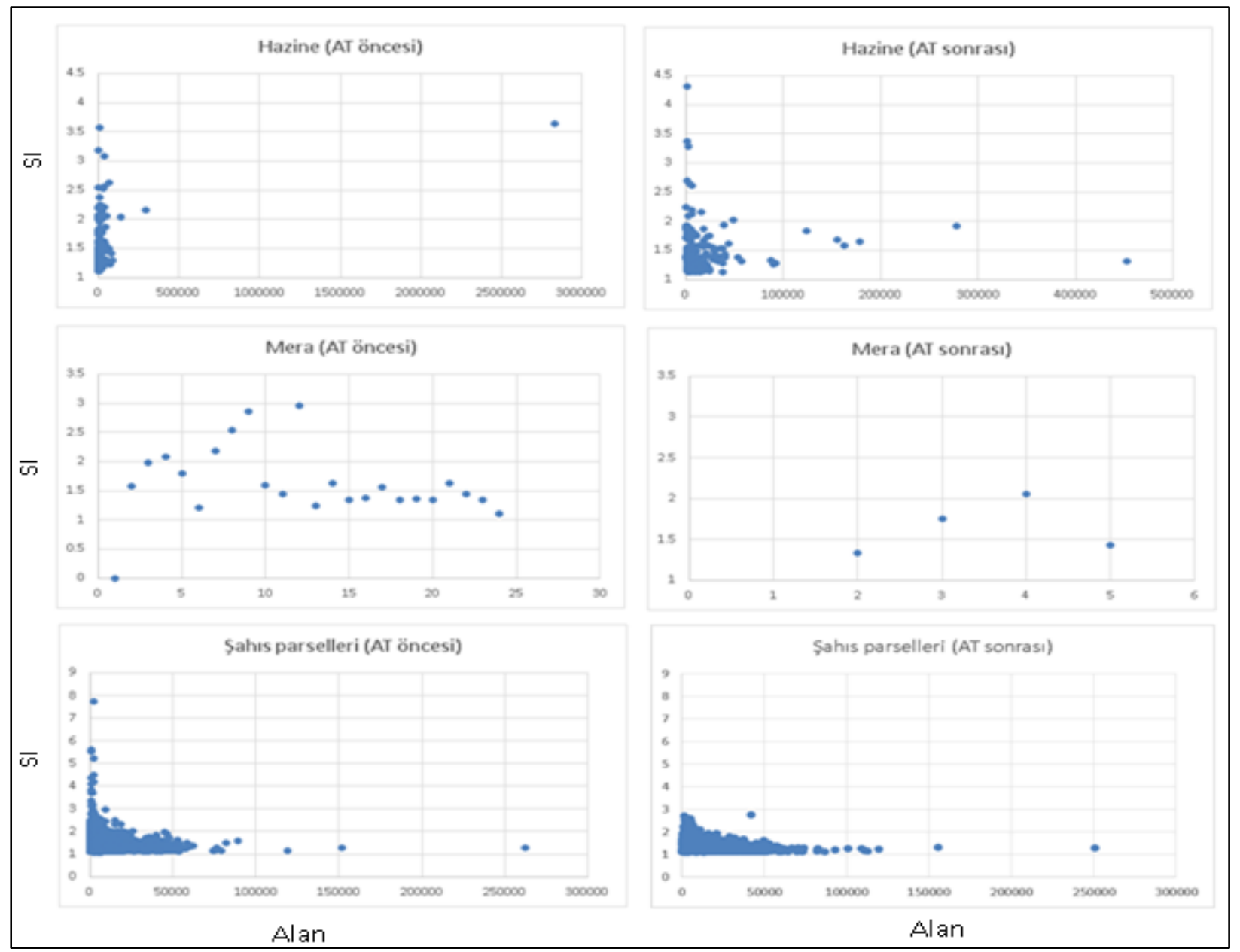

Şekil 5. AT öncesi ve sonrası SI değerleri

Aslan ve ark. (2007) AT yapılan iki köyde SI değerlerini incelemiş̧lerdir. Araştırma yapılan iki köyde ortalama SI değerleri AT öncesi 1.55, (Serem), 1.56 (Beyköy) olarak hesaplamışlardır. AT sonrasında ise bu değerler 1.48 (Serem), 1.54'e (Beyköy) düşmüştür. Arslan ve ark. (2017) Tirhan köyünde 11 işletme üzerinde yaptıkları çalışmada SI değerlerini 1.21-1.58 arasında hesaplamışlardır. Patton (1975) kare ve dikdörtgen gibi geometrik şekiller üzerinde yaptığı çalışmada SI değerlerini 1.13 ve 1.83 arasında bulmuştur. Demetriou ve ark. (2013) yaptıkları çalışmada birbirinden oldukça farklı şekillerin aynı şekil indeksi değerlere sahip olacağını belirtmiştir. Sonuçta AT öncesi SI değerlerini harita üzerinde yakından incelediğimizde düzensiz şekillerin daha yüksek, düzenli ve geometrik (dikdörtgen) şekillerin daha düşük değerler aldığı görülmektedir. Diğer bir deyişle AT sonrası parsel SI değerleri büyük oranda düşmüştür. Bu AT proje mühendislerinin istediği bir durumdur.

Şekil 4'te gösterilen kutu grafiği incelendiğinde AT öncesi hazine parsellerinin FD değerlerinin \%95'inin 1.3639-1.3854, AT sonrası ise \%95'inin 1.3684-1.3957 arasında toplandığ parsellerinin ortalama, maksimum ve minimum FD değerleri sırasıyla $1.3746,1.8848$ ve 1.2633 ; AT sonrası ise $1.3820,17782$ ve 1.2352 olarak hesaplanmıştır. AT öncesi mera parsellerinin FD değerlerinin \%95'inin 1.3282-1.3662, AT sonrası ise \%95'inin 1.2177-1.3559 arasında toplandığı görülmektedir. AT öncesi mera parsellerinin ortalama, maksimum ve minimum FD değerleri sırasıyla $1.3472,1.4239$ ve 1.2404 ; AT sonrası 
ise $1.2868,1.3330$ ve 1.2331 olarak hesaplanmıştır. AT öncesi şahıs parsellerinin FD değerlerinin \%95'inin 1.3841-1.3880, AT sonrası ise \%95'inin 1.3536-1.3581 arasında toplandığı görülmektedir. AT öncesi şahıs parsellerinin ortalama, maksimum ve minimum FD değerleri sırasıyla $1.3860,1.9487$ ve 1.2412 ; AT sonrası ise $1.3558,1.6686$ ve 1.2415 olarak hesaplanmıştır. Fraktal büyüklük indeksi değerleri AT öncesi ve sonrası durumda (Şekil 6) tüm parsel gruplarında istatiksel olarak Paired Samples Test ile karşılaştırılmıştır. AT öncesi ve sonrası durumda Şahıs parselleri FD değerleri arasında istatiksel olarak fark vardır $(\mathrm{P}<0.05)$. Ancak hazine ve mera parselleri arasında istatiksel olarak bir fark bulunmamıştır $(\mathrm{P}>0.05)$.

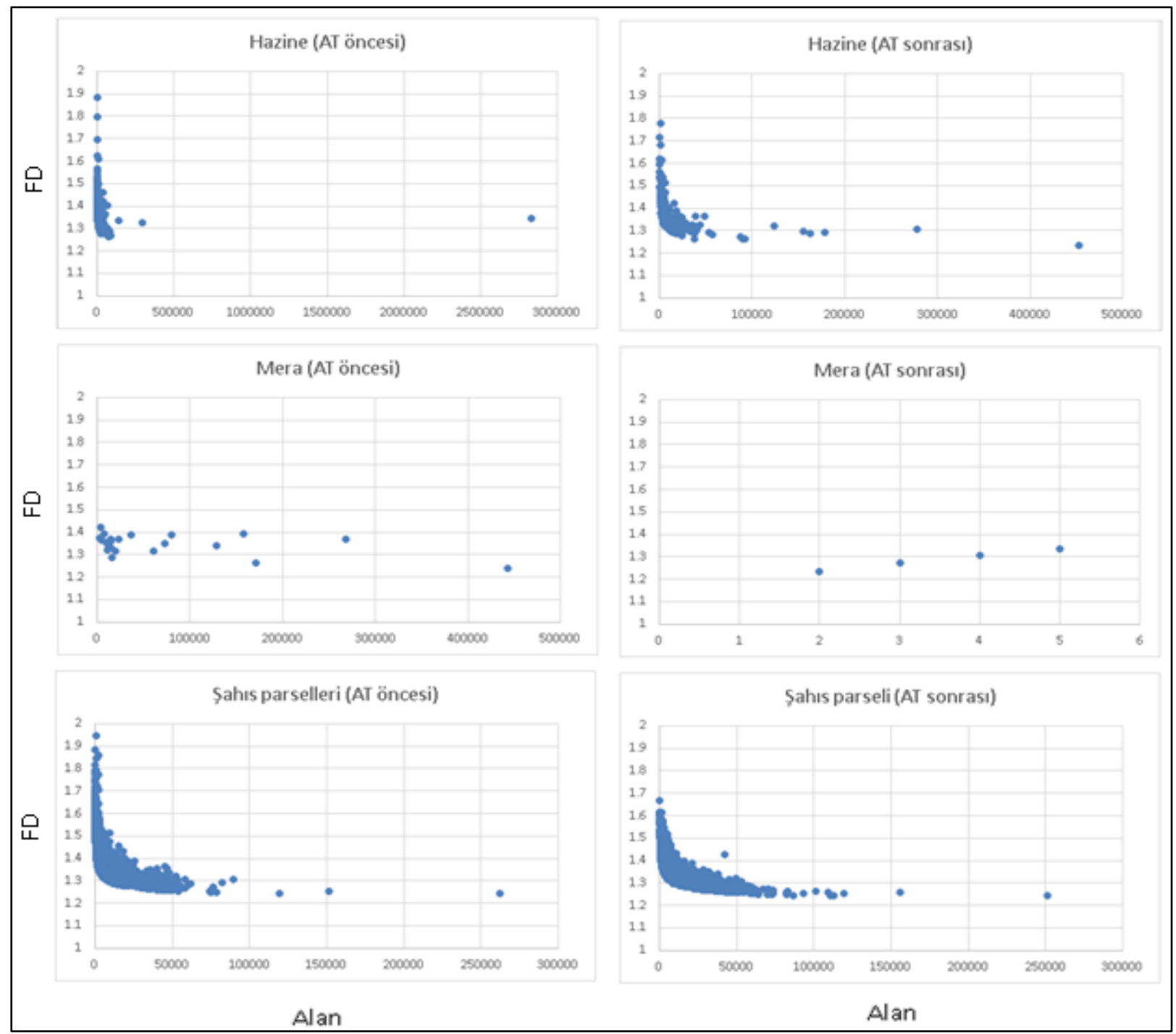

Şekil 6. AT öncesi ve sonrası FD değerleri

Demetriou ve ark. (2013)'te Kıbris'ta arazi parçalanması üzerinde yaptıkları çalışmada benzer geometrik şekillerin farklı FD değerlerini alabileceği (1.354, 1.301 ve 1.262), farklı şekillere sahip parsel şekillerinin ise aynı FD değerlerini (1.375) alabileceğini kanıtlamıştır. Ayrıca FD değerlerinin SI değerlerinden daha kötü sonuçlar verdiğini belirtmiştir. Aslan ve ark. (2007) yaptıkları çalışmada FD değerlerinin SI değerlerine göre daha ayrıntılı bir sonuç verdiğini belirtmiştir. Arazi toplulaştırma öncesi ve sonrasında araştırma alanında FD değerlerini 1.30 ile 1.80 arasında hesaplamışlardır.
Şekil 4'te gösterilen kutu grafiği incelendiğinde AT öncesi hazine parsellerinin FORM değerlerinin \%95’inin 0.5036-0.5519, AT sonrası ise \%95'inin 0.4841-0.5366 arasında toplandığı görülmektedir. AT öncesi hazine parsellerinin ortalama, maksimum ve minimum FORM değerleri sirasıyla 0.5277, 0.8127 ve 0.0753 ; AT sonrası ise $0.5104,0.7848$ ve 0.0535 olarak hesaplanmıştır. AT öncesi mera parsellerinin FORM değerlerinin \%95'inin 0.3440-0.5048, AT sonrası ise \%95'inin 0.1646-0.6436 arasında toplandığı görülmektedir. AT öncesi mera parsellerinin ortalama, maksimum ve minimum FORM değerleri sırasıyla 
0.4244, 0.8094 ve 0.1136; AT sonrası ise $0.4041,0.5653$ ve 0.2367 olarak hesaplanmıştır. AT öncesi şahıs parsellerinin FORM değerlerinin \%95'inin 0.59600.6040 , AT sonrası ise \%95'inin 0.5714-0.5824 arasında toplandığı görülmektedir. AT öncesi şahıs parsellerinin ortalama, maksimum ve minimum FORM değerleri sirasıyla 0.6000, 0.8607 ve 0.0166 ; AT sonrası ise $0.5769,0.8380$ ve -0.7002 olarak hesaplanmıştır. Şahıs parselleri arasında AT öncesi ve sonrası durumda FORM indeksi değerleri istatiksel olarak farklıdır $(\mathrm{P}<0.05)$. Hazine ve mera parselleri AT öncesi ve sonrası durumda FORM indeksi değerleri istatiksel olarak farklılık göstermemektedir ( $\mathrm{P}>0.05)$. FORM ve alan arasında oluşan dağılım Şekil 7'te gösterilmiştir. Jiao ve Liu (2012) Çin'de yaptıkları çalışmada şekil faktörü değerlerini şahıs parsellerinde ortalama 0.58 , min 0.27 , max 0.81 ; mera parsellerinde ortalama 0.11 , min 0.01 , max 0.24 olarak bulmuştur.

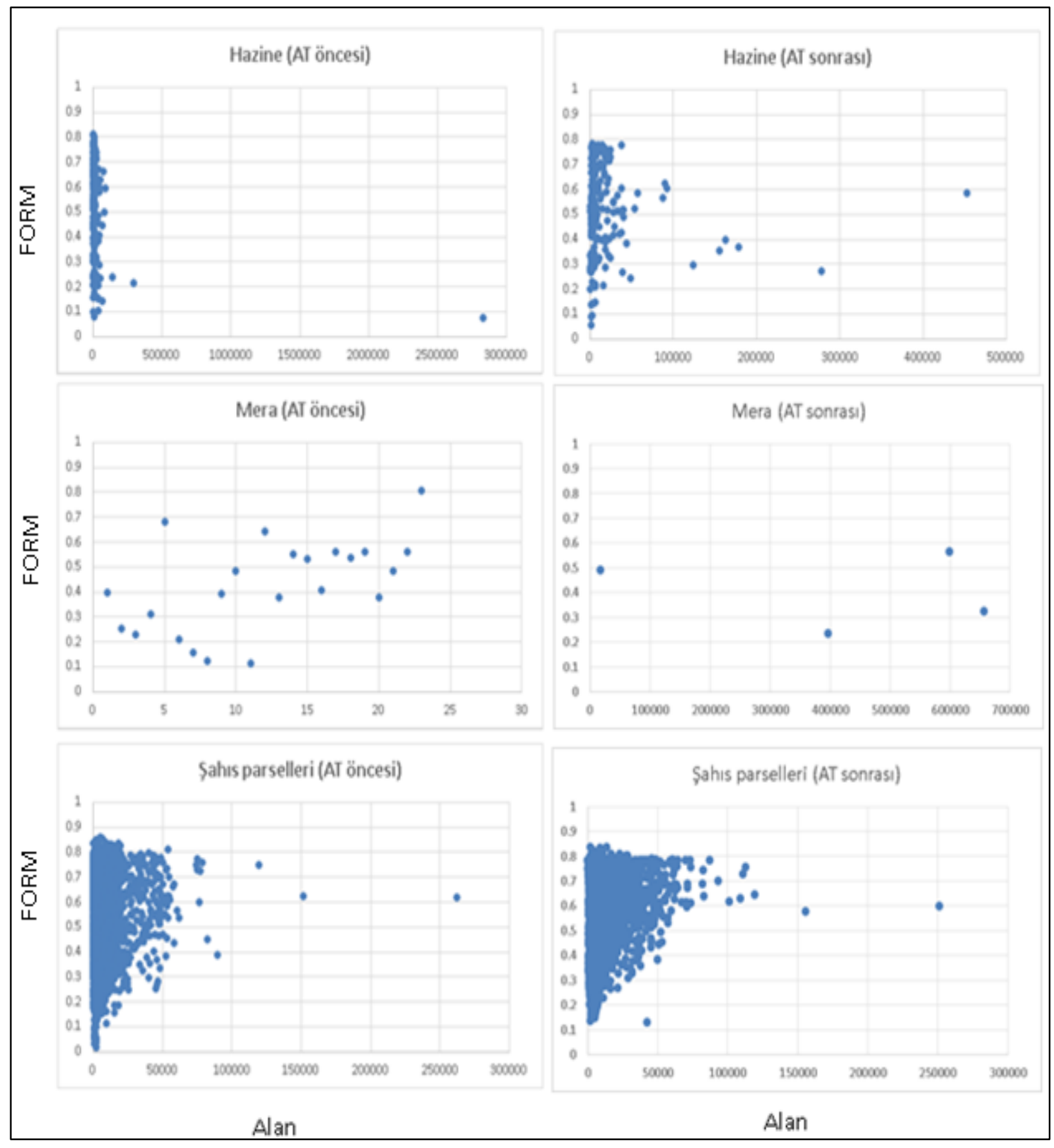

Şekil 7. AT öncesi ve sonrası FORM değerleri

Şekil 4'te gösterilen kutu grafiği incelendiğinde AT öncesi hazine parsellerinin kare piksel ölçeği 
değerlerinin \%95’inin $0.1742-0.2161$, AT sonrası ise \%95'inin $\quad 0.1851-0.2306$ arasında toplandığ görülmektedir. AT öncesi hazine parsellerinin ortalama, maksimum ve minimum $\mathrm{SqP}$ değerleri sirasiyla $0.1952,0.6902$ ve -0.0175 ; AT sonrası ise $0.2078,0.7388$ ve 0.0001 olarak hesaplanmıştır. AT öncesi mera parsellerinin kare piksel ölçeği değerlerinin \%95'inin 0.2095-0.3594, AT sonrası ise \%95'inin $\quad 0.0745-0.5100$ arasında toplandığ görülmektedir. AT öncesi mera parsellerinin ortalama, maksimum ve minimum $\mathrm{SqP}$ değerleri sırasıyla $0.2845,0.6197$ ve -0.0155 ; AT sonrass ise 0.2923 , 0.4509 ve 0.1514 olarak hesaplanmıştır. AT öncesi şahıs parsellerinin $\mathrm{SqP}$ değerlerinin \%95'inin 0.13180.1382 , AT sonrasi ise \%95'inin 0.1466-0.1551 arasında toplandığı görülmektedir. AT öncesi şahıs parsellerinin ortalama, maksimum ve minimum $\mathrm{SqP}$ değerleri sirasıyla $0.1350,0.8545$ ve -0.0471 ; AT sonras1 ise $0.1509,0.5895$ ve -0.0332 olarak hesaplanmıştır.

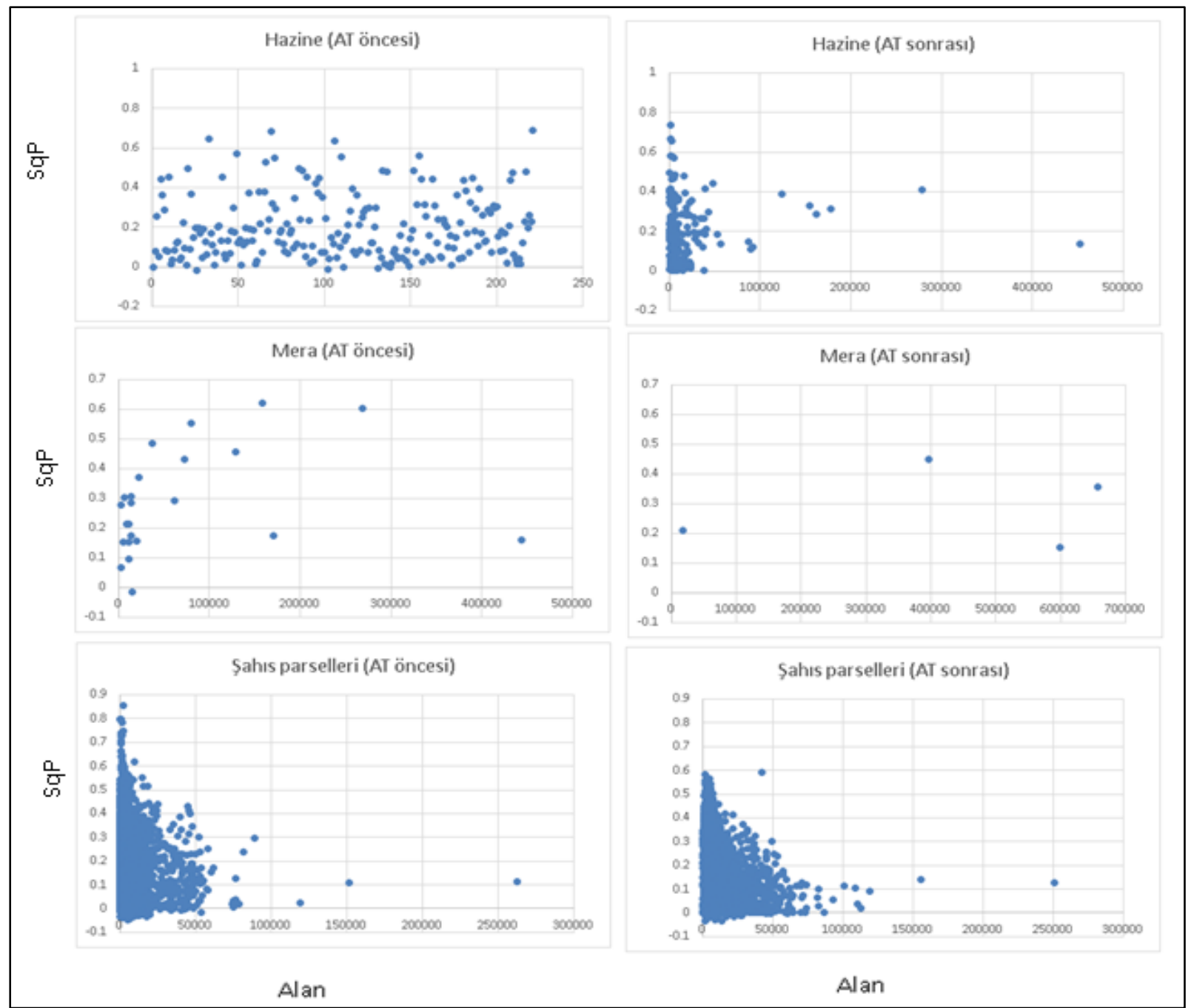

Şekil 8. AT öncesi ve sonrası SqP değerleri değişimi

Jiao ve Liu (2012) Cin'de yaptıkları çalışmada SqP değerlerini değerlerini şahıs parsellerinde ortalama 0.16, $\min -0.09$., $\max 0.40$; mera parsellerinde ortalama 0.62 , min 0.46 , max 0.84 olarak bulmuştur. Şahıs parselleri arasında AT öncesi ve sonrası durumda $\mathrm{SqP}$ indeksi değerleri istatiksel olarak farklıdır $(\mathrm{P}<0.05)$. Hazine ve mera parselleri AT öncesi ve sonrası durumda $\mathrm{SqP}$ indeksi değerleri istatiksel olarak farklılık göstermemektedir $(\mathrm{P}>0.05)$. Araştırmada seçilen bazı parsellerin AT öncesi ve sonrası SqP değerleri Şekil 8'de gösterilmiştir.

\section{SONUÇ ve ÖNERILLER}

$\mathrm{Bu}$ araştırmada Yıldıztepe Köyünde yapılan arazi toplulaştırma projesinde parsel şekillerinin bazı indekslerle değerlendirilmesi amaçlanmıştır. Elde edilen veriler coğrafi bilgi sistemleri kullanılarak sınıflandırılmış ve haritalandırılmıştır. Arazi kullanım sinıflarına göre SI, FD, FORM ve SqP göstergeleri parsel şekillerinin AT öncesi ve sonrası değişimini değerlendirmek amacıyla hesaplanmıştır. Arazi toplulaştırma projelerinin başarısını etkileyen en önemli etkenlerden biri parsel şekilleridir. Parsel şekillerinin düzeltilmesi tarımsal mekanizasyon 
açısından son derece önemlidir. Çiftçilerin ürünlerini yetiştirmede kolaylıklar sağlamakta elde edilen geliri arttırmaktadır. $\mathrm{Bu}$ nedenle parsel şekillerinin tarımsal mekanizasyona uygun bir biçimde gerçekleşmesi ve bu durumun araştırılması önemli bir konudur.

Araştırmada AT öncesi ve sonrası parsel değişimleri ile ilgili tüm bilgiler LiTOP, ArcMAP ve NetCAD yazılımlarından yararlanarak elde edilmiştir. AT öncesi ve sonrası parsellerin geometrik şekilleri araştırılmış şekilsiz parsel sayısı 1391'den 340'a üçgen parsel sayısı 208'den 45'e düşmüştür. AT proje alanında hala şekilsiz parsellerin bulunduğu görülmektedir. $\mathrm{Bu}$ durum AT’nın başarısını sinırlamaktadır.

Ylldıztepe Köyünde AT öncesi 220 hazine, 23 mera ve 5956 şahıs parseli bulunurken, AT sonrası 173 hazine, 4 mera ve 3141 şahıs parseli oluşmuştur. Yapılan analizlerde yukarıda belirtilen bu dört gösterge hesaplanmış ve kutu grafikleri çıkartılmıştır.

Şekil indeksinin birimi yoktur. Bu değer 1'e eşit olduğunda veya yaklaştığında dairesel, kare alanı ifade ederken 1'den uzaklaşan değerler düzensiz ve şekilsiz alanları tanımlamaktadır (McGarigal ve ark., 1995). Şekil indeksi hesaplamalarına göre AT öncesi ve sonrası durumda hazine ve mera parsellerinde istatistiksel fark bulunmaz iken, şahıs parselleri arasında AT öncesi ve sonrası arasındaki fark önemli çıkmıştır. AT öncesi şahıs parsellerinde maksimum değer 7.7580 iken, AT sonrası 2.7497 olarak gerçekleşmiştir. Sonuç olarak AT sonrası indeks değerlerinin AT öncesine istatistiksel bir fark olduğu görülmüştür.

FD'ye göre yapılan değerlendirmede istatistiksel olarak AT öncesi ve sonrası şahıs parselleri arasında fark önemli iken, mera ve hazine parselleri arasında fark bulunmamıştır. Şahıs parsellerinde AT öncesi maksimum değer 1.9487 iken AT sonrası maksimum değer 1.6686 olarak gerçekleşmiştir. Kutu grafiğinde de görüldüğü gibi AT sonrası uç değerlerin önemli ölçüde azaldığı görülmektedir. Sınır değerler yönünden tüm parsellerde AT öncesi duruma göre değerlerin \%95'nin 1'e daha fazla yaklaştığı görülmektedir.

FORM göstergesine göre değerlendirmelerde istatistiksel olarak mera ve hazine parsellerinde AT öncesi ve sonrası durumda fark önemli iken, hazine ve mera parsellerinde fark bulunmamıştır. FORM sınır değerleri 0 ile 1 arasında olması durumunda parsel şekillerinin düzgün geometrik şekillere sahip olacağ öngörülmektedir. AT öncesi şahıs parsellerinde minimum değer 0.0166 iken, AT sonrası minimum değer -0.7002 olarak gerçekleşmiştir. Şekil faktörü kutu grafiği incelendiğinde AT öncesi uç ve aykırı değerlerin olmasına karşın, AT sonrası bu durum ile karşılaşılmamıştır.
$\mathrm{SqP}$ göstergesine göre AT öncesi ve sonrası mera ve hazine arazilerinde istatistiksel fark bulunmaz iken, şahıs parsellerinde fark önemli bulunmuştur. SqP göstergesinde sinır değerler $-0.125^{-1}$ arasında değişmektedir. AT öncesi $\mathrm{SqP}$ değeri bazı hazine parsellerinde (minimum -0.0175) ve şahıs parsellerinde (minimum -0.0155) olarak gerçekleşmiştir. SqP kutu grafiğin incelendiğinde AT öncesi var olan uç ve aykırı değerlerin AT sonrası oldukça azaldığı açık bir biçimde görülmektedir.

AT öncesi ve sonrası veriler üzerinde yapılan istatiksel analizler sonucunda SI, FD, FORM ve SqP değerleri arasındaki özellikle şahıs parsellerinde ilişki önemli olduğu anlaşılmıştır. Sonuçta AT öncesi ve sonrası hesaplanan değerler istenilen sinır değerlerine yaklaşmıştır. Araştırmada indeks değerleri incelendiğinde farklı indeks değerlerinin benzer şekillerde ortaya çıktığ gözlemlenmiştir. Fakat AT sonrası indeks değerlerindeki bu düşüşün AT projelerinde şekil değerlendirme amaçlı kullanılabileceği yargısına varılabilir.

Arazi toplulaştırma sonrasında elde edilen indeks değerleri sınır değerler içinde kalmış yani daha düzgün şekiller oluşmuştur. Araştırmada farklı şekillerin aynı indeks değerleri alabileceği tespit edilmiştir. Ancak arazi toplulaştırma öncesinde şekilsiz parseller azalmış arazi toplulaştırma sonrasında tarımın daha uygun yapılabileceği dikdörtgen şekiller artmıştır. Aynı zamanda indeks değerlerinin optimuma yaklaştığı görülmüştür. Ancak hesaplamalarda şekilsiz bazı parsellerin sınır değerler içinde olduğu gözlemlenmiştir. $\mathrm{Bu}$ nedenle her parselde SI, FD ve FORM göstergelerinin şekil analizinde başarılı bir sonuç vermediği görülmüştür. $\mathrm{SqP}$ göstergesi kare şekline benzer parsellerde optimum değere yaklaştığı görülmüştür. Ancak tarım arazileri 1/7 oranına kadar dikdörtgen şeklinde planlanabildiği için bu tip parsellerde $\mathrm{SqP}$ değerleri parselleri tanımlamakta başarısız olduğu görülmüştür.

Sonuç olarak AT öncesi ve sonrası parsel şekilleri üzerinde yapılan bu araştırmada hisselik durumu, parsellerin geometrik şekilleri ve şekil analizleri sonucunda AT uygulamasının tarımsal mekanizasyon ve çiftçi refahı yönünden oldukça önemli başarılı bir biçimde uygulandığ 1 görülmektedir. Çiftçilerin tarımsal yayım ve eğitim yönünden desteklenmesi gerektiği görülmektedir. Parsel sayılarındaki azalma ve şekillerinin düzeltilmesi çok önemli bir kazanç olarak görülmelidir.

\section{TEŞEKKÜR}

2016/3-32YLS nolu proje KSÜ BAP birimi tarafından desteklenmiş̧tir.

KAYNAKLAR 
Anonim 2017. Arazi Toplulaştırması. http://ankara.tarim.gov.tr/Belgeler/liftet/arazitoplu lastirmasi.pdf Son erişim: 18.12.2017

Arslan F, Değirmenci H, Tonçer R, Yoğun E 2017. Niğde Misli Ovası Tırhan Köyü Arazi Toplulaştırma Projesinin Değerlendirilmesi. 2. Biyosistem Mühendisliği Kongresi, Tokat.

Arslan H, Tunca, E. 2013. Arazi Toplulaştırmasının Sulama Projelerinin Performası Üzerine Etkileri. Anadolu Tarım Bilim. Dergisi, 2013,28(3):126-133.

Aslan T, Gundogdu K, Arici I 2007. Some Metric Indices for the Assessment of Land Consolidation Projects. Pakistan Journal of Biological Sciences, 10(9), 1390-1397.

Boyacıŏlu R 1975. Arazi Toplulaştırılması Yapılan Erzincan Güllüce Köyündeki Tarımsal İşletmelerin Ekonomik Analizi. Topraksu Teknik Dergisi, Sayı:57, Ankara, 131s.

Boztoprak, T, Demir O, Çoruhlu YE, Nişancı R 2015. Arazi Toplulaştırmasının Tarımsal İşletmelere Etkilerinin Araştırılması. Selcuk University Journal of Engineering, Science And Technology, 3(3), 1-11.

Çelebi M 2010. Toplulaştırmanın Karaman İlinde Sulama ve Diğer Tarımsal Faaliyetlerin Verimliliği Üzerinde Etkileri. Tarım Bilimleri Araştırma Dergisi, 3(2), 1-6.

Demetriou D 2013. The Development of an Integrated Planning and Decision Support System (Ipdss) for Land Consolidation. Springer Science \& Business Media.

Frohn RC 2006. The Use of Landscape Pattern Metrics in Remote Sensing Image Classification, International Journal of Remote Sensing, 27(10), pp. 2025-2032.
Gonzalez XP, Alvarez CJ, Crecente R 2004. Evaluation of Land Distributions with Joint Regard to Plot Size and Shape. Agricultural Systems, 82(1), 31-43.

Jiao L, Liu Y 2012. Analyzing the shape characteristics of land use classes in remote sensing imagery. ISPRS Annals of Photogrammetry, Remote Sens. Spatial Inf. Sci., I-7, 135-140.

Kara M 1984. Sulama Şebekelerinde Sulama OranıArazi Parçalanması Şebeke Yoğunluğu İlişskileri ve Türkiye'deki Durum Üzerine Bir Araştırma. Akdeniz Üniversitesi Isparta Mühendislik Fakültesi İnşaat Mühendisliği Bölümü, Isparta, $45 \mathrm{~s}$

Lewis HG, Cote S, Tatnall ARL 1997. Determination of spatial and temporal characteristics as an aid to neural network cloud classification. International Journal of Remote Sensing, 18, pp. 899-915.

Libecap G, Lueck D 2009. The Demarcation of Land and the Role of Coordinating Institutions. Cambridge, Ma, National Bureau Of Economic Research Working Paper No. 14942.

Mcgarigal K, Marks B 1995. FRAGSTAT: Spatial Pattern Analysis Program for Quantiy Fying Landscape Structure.

Patton DR 1975. A Diversity Index for Quantifying Habitat" Edge". Wildlife Society Bulletin (19732006), 3(4), 171-173.

Russ JC 2002. The Image Processing Handbook, fourth ed. CRC Press, Boca Raton, FL.

Sönmezyıldız E 2012. Eskişehir Beyazaltın Köyü Arazi Toplulaştırma Alanında Sulama Performansının Değerlendirilmesi. Ankara Üniversitesi Fen Bilimleri Enstitüsü Tarımsal Yapılar ve Sulama Anabilim Dalı, Yüksek Lisans Tezi, Ankara.

Yoğunlu A 2013. Arazi Toplulaştırma Faaliyetleri. Trb1 Bölgesi (Bingöl, Elazığ, Malatya, Tunceli), Firat Kalkınma Ajansı. Erişim Tarihi: 2013. 